\title{
Bem te Quero - Da Educação Parental à Promoção dos Direitos da Criança
}

\section{Bem te Quero- Parental education and promotion of children's rights}

\author{
Sara Tavares**, Sara Pacheco*, Joana Amen*, Beatriz Lopes*, Marina Sousa**, Suzana Nunes Caldeira***, Célia \\ Barreto Carvalho**** \\ * Patronato de São Miguel, Portugal \\ ** “Departamento de Ciências da Educação, Universidade dos Açores, Portugal” \\ ***Universidade dos Açores - CICS.NOVA.UAçores, Portugal \\ ****Universidade dos Açores e Centro de Investigação do Núcleo de Estudos e Intervenção Cognitivo-Comportamental, Portugal
}

\begin{abstract}
Resumen
É na primeira infância que existe maior disponibilidade das figuras parentais para o estabelecimento de relações positivas e de afeto. É também neste período que muitos cuidadores sentem dificuldades em responder às necessidades das crianças. Neste sentido, surge a necessidade de desenvolver e implementar o Bem-Te-Quero (BTQ), um Programa de promoção de competências parentais para famílias com filhos até aos 18 meses. O BTQ enfatiza a promoção de competências parentais favorecedoras da qualidade da relação pais-bebé, dado esta ser apontada como um dos principais preditores da saúde psicológica nos vários estádios do desenvolvimento.

Palabras clave: cuidados infantis, processos interpessoais e grupais, serviços sociais e comunitários
\end{abstract}

\begin{abstract}
During early childhood there is greater availability of parental figures to establish positive relationships and affection. It is also during this period that many carers find difficulties to meet the childrens'needs. In this sense, arises need to develop and implement Bem-Te-Quero (BTQ), a promotional program of parenting skills for families with children up to 18 months. BTQ emphasizes the promotion of parenting skills favoring the quality of the parent-child relationship, being one of the main predictors of psychological health in various stages of development, as well in babys's developmental gains

Keywords: childrearing \& child care, group \& interpersonal processes, community \& social services
\end{abstract}

Diversos estudos têm sublinhado a importância da família como o primeiro contexto ambiental que o indivíduo conhece e com o qual interage (Bry, 1996; Relvas, 1996). A família constitui o núcleo-base da organização social e o contexto natural para o crescimento, bem-estar e proteção da criança.

Contextos familiares propiciadores de cuidados parentais satisfatórios e tranquilizantes nos domínios físico, social e afetivo, num período precoce da vida, oferecem à criança maiores oportunidades de construção de uma representação positiva de si, surgem como suporte para uma exploração ativa e autónoma do meio, assim como, constituem prognóstico de sucesso escolar e ajustamento social (Costa, Teixeira \& Gomes, 2000).

Segundo Cruz (2005) as funções da parentalidade abarcam a satisfação das necessidades básicas de sobrevivência e saúde da criança, as necessidades de compreensão cognitiva das realidades extra-familiares, as necessidades de afeto, confiança, segurança e de interação social da criança, com espaços organizados e previsíveis, objetos e tempo que possibilitem a existência de rotinas. A literatura aponta, ainda, para a importância de se abordarem as questões relativas à estimulação a quatro níveis: psicomotora, cognitiva, sensorial e social na primeira infância (Coll, Marchesi, Palácios, et al., 2004).

De acordo com Zuzarte e Calheiros (2010), é no contexto familiar que as crianças exercitam as competências adquiridas mencionadas anteriormente com e sob orientação de adultos de referência. Esta relação constitui-se como um recurso emocional e cognitivo e permite que a criança explore os contextos envolventes. Sabendo-se que as crianças concretizam a sua partcipação ativa na vida social, através das observações que fazem e das orientações que recebem dos pais, prevê-se que, quanto mais consistentes forem as interacções entre a díade parental, melhores serão as interações da criança com os outros e mais adaptativas serão as suas vivências socias.

O quadro normativo da Convenção dos Direitos da Criança tem proposto o desenvolvimento e implementação de programas de educação parental, de cariz psicopedagógico e social, no sentido de conferir aos pais a responsabilidade de cuidados à criança. A educação parental deve ser entendida como um direito a que os pais podem ter acesso e que lhes permita assegurar as melhores condições de sobrevivência, de desenvolvimento, de protecção e de livre participação das suas crianças.

Em termos de programas de promoção de competências parentais, verifica-se escassez de programas para famílias com bebés. Deste modo, e na procura de respostas para necessidades concretas sentidas em contexto profissional, desenvolveu-se um Programa de Promoção de Competências Parentais, designado por Bem-Te-Quero (BTQ). O BTQ foi concebido para ser aplicado em famílias de nível sócio-económico carenciado, com bebés dos 0 aos 18 meses de idade. Com este programa pretende-se que as mães e/ou outros cuidadores fortaleçam o vínculo afetivo com os seus bebés e, simultaneamente, desenvolvam as suas capacidades parentais. Pretende-se também que as mães e/ou outros cuidadores desenvolvam outras competências do domínio pessoal e interpessoal. Por último, o BTQ pretende ainda identificar e reforçar forças e processos de resiliência familiar. 


\section{Método}

\section{Participantes}

O BTQ, nesta fase, destina-se a famílias, benificiárias do Rendimento Social de Inserção (RSI), com bebés dos 0 aos 18 meses de idade e a residirem na ilha de São Miguel, Açores, Portugal.

\section{Instrumentos}

Estão previstos mecanismos de regulação das atividades a desenvolver com o BTQ que passam por avaliações utilizando processos de recolha de dados de enfoque qualitativo, tais como diários de bordo, grelhas de observação de comportamentos e registo de incidentes críticos e de verbalizações dos participantes. Está também prevista a utilização de uma ficha de avaliação a preencher pelo participante no final do programa onde este pronuncia em termos de grau satisfação sentida por participar no BTQ.

\section{Procedimentos}

A identificação das famílias beneficiárias do Rendimento Social de Inserção (RSI) com dificuldades ao nível do exercício da parentalidade ou em risco psicossocial será efectuada por profissionais do Instituto de Desenvolvimento Social dos Açores. As famílias serão convidadas a participar no BTQ, sendo esta participação livre e voluntária.

Em termos da intervenção, o programa é composto por 19 sessões, com duração de 60 minutos cada. As sessões correspondem a cinco áreas temáticas principais, a saber: Estimulação, Segurança, Cuidados Básicos, Forças Familiares e Práticas Educativas Parentais.

Os dados que permitiram clarificar impactos do BTQ, a partir dos instrumentos antes mencionados, serão analisados através da análise de conteúdo e de procedimentos de estatística descritiva.

\section{Resultados Esperados}

Espera-se que o BTQ se possa transformar num programa de educação para a parentalidade que, através da promoção da reflexão e da ação dos pais, concorra para a promoção do desenvolvimento da criança em contexto familiar. Mais especificamente, aspira-se a que os pais/cuidadores se sintam mais capacitados para cuidar dos seus bebés, que os processos de funcionamento familiar saiam robustecidos e facilitados, que a relação diádica seja fortalecida e vivida positivamente e que haja franco benefício para o comportamento e/ou desenvolvimento da criança.

página completa $(16,5 \mathrm{~cm})$, responsabilizándose los autores de su composición.

\section{Referencias}

Bry, B. H. (1996). Psychologycal approaches to prevention. In Bickel, W. K. \& DeGranpre (Eds) Drug Policy and Human Nature - psychological perspectives on the prevention, management, and treatment of illicit drug abuse (p. 55-76). Nova Iorque: Plenum Press.

Coll, C., Marchesi, A., Palácios, J. \& cols.(2004) Desenvolvimento psicológico e educação. (Vol. 3). Porto Alegre: Artmed.

Costa, F., Teixeira, M. \& Gomes, W. (2000). Responsividade e Exigência: Duas Escalas para Avaliar Estilos Parentais. Psicologia: Reflexão e Crítica, 13(3), 465-473.

Cruz, O. (2005). Parentalidade. Coimbra: Quarteto.

Organização das Nações Unidas (1989). Assembleia Geral das Nações Unidas. Convenção das Nações Unidas sobre os Direitos da Criança.

Relvas, A. P. (1996). O ciclo vital da família. Perspectiva Sistémica. Porto: Edições Afrontamento.

Zuzarte, M. \& Calheiros, M. (2010). Programa de intervenção nas interacções pais-filhos "Desenvolver a Sorrir” - Estudo exploratório. Análise Psicológica, 3 (XXVIII), 491-504. 